\title{
A Gestão do Design no gerenciamento do processo de novos produtos: Design Estratégico, Propriedade Intelectual e Certificação, aplicados em um brinquedo pedagógico.
}

\author{
The Management of the Design in the management of the process of new products: \\ Strategical Design, applied Copyright and Certification in a pedagogical toy.
}

\author{
VIEIRA, Alexandre Jr. Franco; Especialista; \\ Universidade Estadual de Londrina \\ alexandrefv.design@gmail.com
}

\begin{abstract}
RESUMO
Este artigo tem como objetivo propor uma ferramenta de gerenciamento e planejamento de novos produtos, para um brinquedo de cunho pedagógico, com base na Gestão de Design e nos direitos da propriedade intelectual. De natureza exploratória, possui como metodologia, entrevistas e uma abordagem a respeito das leis do direito de propriedade, e de certificação de produtos. Apresenta como resultado, a proposição de ações para a Gestão de Design do brinquedo pedagógico, por meio de um modelo visual de planejamento de projetos, e as respectivas ações cabíveis a fim de validar um novo produto com proteção legal a garantir sua legitimidade.
\end{abstract}

Palavras Chave: Gestão do Design; Propriedade Intelectual; Planejamento de novos produtos.

\begin{abstract}
This article has as objective to consider a management tool and planning of new products, for a toy of pedagogical matrix, with bases in the Management of the Design and the Intellectual property rights. Of investigative nature, it possesss as method open interviews and a boarding regarding the laws of the property right. It presents as resulted, the proposal of action for the Management of Design of the pedagogical toy, by means of a visuail model of planning of projects, and the respective actions in order to validate a new product with legal protection to guarantee its legitimacy.
\end{abstract}

Keywords: Management of the Design; Copyright; Planning of the news products.

\section{Introdução}

O desenvolvimento de um novo produto possui uma série de informações e necessidades específicas que o precedem, visando a maioria das vezes um público característico em potencial. As funções destes produtos, bem como suas qualidades e diferenciais disponibilizados, devem buscar a melhor adequação dessas necessidades em conjunto com meios distintos de se atrair e satisfazer esse mesmo público alvo. Assim, o Projeto de Produto preza pela importância dessas premissas referentes ao usuário/produto desde a coleta de dados e informações, desenvolvimento, produção, distribuição e descarte e todo e qualquer complemento que acercam como foco essa prática projetual.

O produto focado no planejamento desta gestão é um brinquedo de cunho pedagógico, desenvolvido para auxiliar crianças com idade a partir de sete anos. A função principal que norteia o desenvolvimento e projeto deste produto é uma determinada carência de materiais didático/ pedagógicos que estimulem e corrijam o desenvolvimento motor e cognitivo dos infantes nessa faixa etária. Logo, é conexo afirmar que a disponibilidade de um produto que atenda tais exigências 
A Gestão do Design no gerenciamento do processo de novos produtos: Design Estratégico, ... pedagógico.

apresente um direcionamento plausível de gestão, no intento de promulgar o brinquedo, para que se torne possível o acesso do público alvo a este brinquedo.

Este artigo apresenta como objetivo, propor um padrão de planejamento baseado na Gestão do Design, direcionando o produto a uma série de padrões e práticas que auxiliem a proteção legal do design, bem como a proposta de um modelo que facilite o entendimento acerca de planejamento e implantação para comercialização do brinquedo. Deste modo, faz-se necessário um estudo específico acerca da Gestão do Design, metodologias para a criação de um novo produto e informações sobre registros de propriedade e certificação, além de entrevistas com profissionais da área, sendo pertinentes essas etapas na provisão de produtos bem estruturados e de qualidade para o usuário, com legitimidade e segurança.

Além disso, é pertinente afirmar que o conforto dos pais, ao adquirir um brinquedo preza por diversos itens que colocam a segurança do infante e a qualidade do produto como itens de necessária importância para auxiliar a criança no desenvolvimento de sua formação estrutural e mental. Assim, tal valor percebido é dado como garantia de confiança e forma de resguarde nas condições do brinquedo a ser comercializado.

O planejamento estratégico para o lançamento de novos produtos deve ser direcionado especificamente a criar um novo espaço no mercado, oferecendo aos consumidores e público alvo, o diferencial aliado ao custo reduzido e á oferta de melhor utilidade para o comprador. É relevante que o planejamento apresente a integração destes fatores, ao minimizar também os riscos e prezar pelo foco de seu produto e aos objetivos pertinentes com o mercado.

Todavia, para que o planejamento do produto seja bem direcionado, é necessária a proposta de um modelo de Gestão de Design que enfoque em seu plano de gerência, a verificação de novos métodos e ferramentas de lançamento. Segundo Kim (2005), "A inovação de valor é uma nova maneira de raciocinar sobre a execução da estratégia, que resulta na criação de um novo espaço de mercado e no rompimento com a concorrência". Destarte, percebe-se que ao firmar o desenvolvimento de um produto em mercados e nichos não explorados, por si já se cria uma nova demanda.

Esta estratégia apresentada por Kim (2005), em sua obra "A Estratégia do Oceano Azul" pode ser utilizada como ferramenta de planejamento, uma vez que coloca o produto e seu público alvo como uma demanda inexplorada, abrangendo assim as possibilidades quanto á diferenciação e enfoque no baixo custo. Trata-se de um instrumento eficaz que tem por excelência "minimizar os riscos, não em assumir riscos ás cegas" Kim (2005) com propostas de ferramentas apresentadas de maneira práticas que tem por finalidade ir além de apenas uma visão analítica de gestão.

Outro método de auxílio que pode ser relacionado ao lançamento de novos produtos é o Design Thinking. Apresentada por Tim Brown (2010), no livro "Design Thinking, Uma metodologia poderosa para decretar o fim das velhas idéias", ele propõe diferentes tipos de abordagens, tanto no campo da criação e lançamento de novos produtos, quanto na execução e prestação de serviços. A princípio, o exposto leva em consideração o integrar do ponto de vista humano, sob a ótica do design, mas difundido de modo que quaisquer pessoas possam aplicá-las de maneira inovadora para solucionar problemas.

Segundo Newton (2011) "com relação à gerência de projeto é necessário “..ter um mecanismo de fornecimento de informações para entender quando a ação de gestão é exigida e, por fim, implementar uma ação quando a informação lhe disser que isso é necessário". Com base nesta afirmação, podese perceber a importância em se definir os aspectos operacionais que norteiam o desenvolvimento de um produto, em conjunto com a elaboração de um programa baseado em alicerces que norteie expectativas, escopo, plano e recursos.

Deste modo, conforme Newton (2011) o programa e o monitoramento contínuo do projeto devem ser efetivos de modo a ter um mapeamento do processo, conforme o plano e o uso de ferramentas como análise de valor agregado. Assim, "para se angariar resultados satisfatórios a gerência de projetos deve estar ciente da gama de ferramentas em seu arsenal e usá-las de modo apropriado."

Faz parte da metodologia deste artigo, uma pesquisa em conjunto com o IPEM (Instituto de Pesos e Medidas) e com o INPI (Instituto Nacional de Propriedade Intelectual). Este propósito visa 
buscar informações e procedimentos que acercam a legitimação de um produto tanto em aspectos físicos e de qualidade em meio a testes, quanto em questões de legalidade e proteção do design.

A proteção de desenhos e patentes é concedida por meio de Registro no INPI, através de uma série de procedimentos e exames. De acordo com Cunha (2000), o exame formal do pedido, assim como os critérios tomados, é considerado a partir do conceito de desenho industrial emitido por Lei. Logo, os pedidos de registro são analisados conforme a natureza de sua proteção e seu devido posicionamento perante normas.

Assim sendo, é pertinente que a Gestão de Design aborde as ações necessárias para a validade de um produto frente aos órgãos já citados, convenientemente propostos por um padrão de GD que tenha em seu conteúdo a propriedade e os direitos legais no processo de planejamento de suas intervenções.

As chances para que um produto novo seja bem aceito pelo seu público alvo, derivam de uma forte orientação para o mercado, bem como benefícios e valores, que agreguem diferenciação entre produtos concorrentes, proporcione qualidade e atenda as necessidades do consumidor. Nesse aspecto o projeto de um brinquedo direcionado a infantes da faixa de 7 anos, requerem estudos e informações segundo suas necessidades básicas em desenvolvimento.

Este estudo, outrora realizado em projeto, buscou sanar as dificuldades do desenvolvimento motor e cognitivo da faixa etária, visando um posterior aprendizado de modo integrado entre o pensar e o modo de executar atividades propostas. Por meio de metodologias específicas, ferramentas de criação e grafismos direcionados, obtiveram-se o modelo de um produto que atende tais exigências perante o desenvolvimento integrado, estimulando a criança e seu empenho frente a desafios propostos.

O produto, diante de pesquisas e testes com o público alvo, por meio de protótipo, afirmou a confiabilidade frente às informações coletadas e os métodos utilizados durante o desenvolvimento do produto. Entretanto, apesar do brinquedo satisfazer as necessidades específicas do infante, o consumidor em potencial que define o ato da compra são os Pais. Destarte, esse consumidor no momento da compra, preza por qualidade, segurança, preço e benefício que o brinquedo tende a proporcionar para criança.

Faz-se jus, portanto que o produto possua uma forte orientação para esse mercado, com benefícios e valores, que agreguem segurança, qualidade nos materiais, baixo custo, atendendo as necessidades do consumidor e do público alvo. Garantir os atributos citados, de maneira a promover o desenvolvimento integrado da criança e o conforto e a tranqüilidade dos Pais ao adquirir o brinquedo é uma prerrogativa favorável para o lançamento, legitimidade e sucesso do produto.

Além disso, todos os processos de viabilidade técnica e legal destes padrões garantem eficácia com base na validade de todo o projeto, garantindo uma cumulação de informações, pesquisas e testes que se incorporam ao produto. Esses aspectos comerciais e técnicos devem ser conduzidos com o propósito de influenciar diretamente no êxito do produto, tornando o projeto mais eficaz, a fim de reduzir custos, incertezas do meio e acrescentar conhecimento ao projeto.

Deste modo justifica-se a aplicação de uma Gestão de Design, centrada no Design Estratégico com foco na importância do Direito de Propriedade Legal, no propósito de investigar métodos e ferramentas, buscar os aspectos do planejamento de novos produtos e pesquisar junto ao INPI e IPEM questões a legitimar propriedade legal do design, integrando assim essas práticas a fim de propor um modelo de gestão do brinquedo e validar o projeto.

\section{Gestão do Design}

Gestão de Design compreende uma atividade que compete tanto em nível estratégico, quanto em operacional acerca de um produto ou corporação, buscando como base a integração e inter-relação entre as funções. Do mesmo modo, o presente artigo, sugere a partir do Design Estratégico a busca em informações que vão além do desenvolvimento do produto, explorando estratégias de lançamentos e diagnósticos de procedimentos para se legitimar a Propriedade Intelectual.

É necessário estabelecer um planejamento coerente, fundamentado no consumidor, público 
A Gestão do Design no gerenciamento do processo de novos produtos: Design Estratégico, ... pedagógico.

alvo e em suas motivações, o que sugere uma profunda compreensão acerca dos fatores envolvidos. Conforme Harrison (1990), um dos primeiros passos chaves para o êxito do gestor de produto é conhecer seu produto melhor do que qualquer outra pessoa.

Para se angariar os objetivos da gestão, a busca por diferentes ferramentas de planejamento visando á diferenciação do novo produto é conexa, ao se estabelecer critérios e fatores que proporcionam maior foco no lançamento do produto. Para isso, é necessário dominar as técnicas de planejamento, programação e acompanhamento de atividades. A coleta de informações acerca do registro de propriedade é efetiva em se tratando de garantir a proteção legal do produto e regularizálo para posterior comercialização.

Segundo Fricke (apud Philips, 2007) "A gestão de design contribui para definir os perfis dos consumidores e os valores a serem adicionados aos produtos e serviços." Ele também afirma que a atividade de design influi na identidade da corporação e afeta diretamente as operações e os consistentes objetivos estratégicos da empresa.

Logo, é pertinente que a gestão de design busque estabelecer uma série de atividades que acompanhem o planejamento de maneira eficaz, corroborando fatores que podem se tornar limitantes para o lançamento e comercialização, nas etapas posteriores após a criação e materialização do produto.

Como parte da prática na gerência de Design, é comum encontrar em andamentos de projetos, certas dificuldades devido a inovações que muitas vezes não são bem aceitas. Para isso, uma forma de sobrepujar essas dificuldades durante o processo de gestão, afirma Philips (2007), é listar tais obstáculos futuros e preparar-se antecipadamente.

A metodologia do projeto possui duas formas de atuações, segundo Magalhães (1997): uma se diz respeito à concepção do produto, vinculado a processos de criação, métodos e técnicas de desenvolvimento; o outro diz respeito ao planejamento e a programação, vinculados a um controle relacionado a uma determinada característica cronológica. Sendo então neste segundo momento, inerente á concepção do produto, que o planejamento do brinquedo deve ser estruturado.

Portanto, no decorrer deste artigo serão utilizados alguns guias e instrumentos de mensuração da Gestão de Design como:

- Design Thinking, Uma ferramenta poderosa para decretar o fim de velhas idéias, Brown (2011)

- A Estratégia do Oceano Azul, Como criar novos mercados e tornar a concorrência irrelevante, $\operatorname{Kim}(2005)$

- O Gestor de Projetos Newton (2011)

- Projeto de Produto, Baxter (1998)

- A Gestão do Design como Estratégia Organizacional, Martins (2008)

Conforme Martins (2008), a gestão pode ser realizada em processos paralelos: Gestão Estratégica de Design (referente à estrutura organizacional de uma empresa) e Gestão Operacional do Design (DNP), sendo que os processos operacionais se equivalem á realização ativa do projeto e examinados constantemente, por meio de objetivos, pelo design estratégico.

Uma questão muito importante que diz- se a respeito no exercício da gestão, é relacionado aos aspectos e atividades táticas. Phillips (2007), afirma que os designers preocupam-se apenas com essas atividades, raramente colocando em questão atividades de ordem estratégica. Portanto, existe uma visível necessidade por parte do gestor de design, em atuar em assuntos de maior ordem estratégica, com a finalidade de saber nitidamente sobre as dificuldades a serem solucionadas.

Sob esta ótica de planejamento é que a coleta de informações acerca do registro de propriedade é efetiva em se tratando de garantir proteção legal do produto e regularizá-lo para posterior comercialização. A gestão do design contribui deste modo ao tomar conhecimento das práticas e etapas de registros e certificação, e complementar essas atividades estratégicas no planejamento, visando oferecer um produto com suporte nos âmbitos propostos.

Turner (apud Philips, 2007), ressalta que o "Design é um essencial elemento ao adicionar 
VIEIRA, Alexandre Jr. Franco

valores desejados pelo consumidor, por meio de produtos e serviços, e completa" significa definir o que os consumidores desejam aquilo que a empresa pode oferecer. Assim, o gestor de design participa na construção da visão estratégica, em um importante contexto ao perceber o perfil dos consumidores e definir como a empresa o pretende atender.

Entretanto, a Gestão de Design requer além de instrumentos e meios de se gerir aspectos que norteiam o projeto de produto, informações que acercam a dinâmica humana, a interpessoabilidade e compreender economia e criatividade nos negócios, afirma Lombardi (1998). Deve apresentar competências pessoais ao saber administrar recursos e gerenciar equipes, sempre pensando estrategicamente para se obter êxito nos objetivos planejados, complementa o autor.

Assim, percebe-se a necessidade acerca da Gestão de Design e do planejamento bem elaborados, com o propósito de se alcançarem êxito nos resultados por meio dos objetivos programados. Muito além, a gestão deve abordar toda a questão estratégica, visando à implementação do Design como meio de pensar a todas as unidades corporativas, através de ferramentas, mas também por meio do ímpeto, do empreendedorismo e do senso de liderança.

\section{Sobre o Planejamento e o lançamento de novos produtos}

Baxter (1998) propõe que no planejamento do projeto, devem-se estabelecer alguns marcos importantes do processo, definindo assim as ocasiões em que serão feitos os controles, e se possível coincidindo com as principais decisões a serem tomadas. Para isso, existem gráficos de auxílio para se programar as tarefas, como o PERT (Programme Evaluation and Review Tchnique) Segundo Baxter(1998) esse gráfico "..identifica as ligações de precedência entre todas as atividades e mostra quais são as atividades que devem ser completadas antes que outra possa ser iniciada".

Através deste instrumento, pode-se mensurar e determinar o caminho crítico, pois havendo qualquer atraso, a duração e as outras atividades podem ser afetadas. Entretanto, Baxter expõe também 6 conceitos chaves para um planejamento de Produto. São eles:

- Valor para o consumidor - A chave do sucesso de um produto com base nas especificações, de modo a adicionar esse valor.

- Modelo Kano de qualidade- Satisfação do consumidor em três fatores de qualidade balanceados: básico, desempenho e excitação.

- Desdobramento da função qualidade (QFD)- Transforma as necessidades do consumidor em requisitos de projeto, que podem ser priorizados com base na análise de produtos concorrentes ou por sistema de importância.

- Especificação do projeto - Detalhamento do projeto seguindo requisitos de fabricação, distribuição, vendas, manutenção conforme impostos, normas e leis.

- Programação do projeto - Estabelecimento de etapas do desenvolvimento do produto, com base nas etapas, estabelecendo-se os prazos e pontos determinados para o controle de qualidade.

- Atribuição de responsabilidades - atribuição de tarefas e responsabilidades de execução, com retorno de relatos periódicos de desempenho a superiores ou coordenação.

Conforme Martins (apud Mozota, 1998), a Gestão do Design se enriquece com os aspectos da gestão, e o Design se beneficia com esses conceitos, abrindo portas para o gerenciamento por meio do Design. Ou seja, é o gerenciamento de informações de uma situação percebida, organizadas de modo a se alcançar uma realidade projetada. Desta forma, o modelo atua como uma simulação de atividades da Gestão a serem integradas e executadas.

O Modelo, "Disco" Integrador da Gestão do Design, proposto por Martins e Merino (2008), é um exemplo de instrumento que permite a visualização da aplicação do design em uma composição organizacional, abordando por meio do design operacional e estratégico, processos e agentes internos e externos à estrutura. Ela proporciona uma inter-relação entre diversos aspectos tanto externos quanto internos, inerentes á tomadas de decisões, que podem ser readequadas conforme o "disco" 
gira, possibilitando sempre uma mudança no padrão.

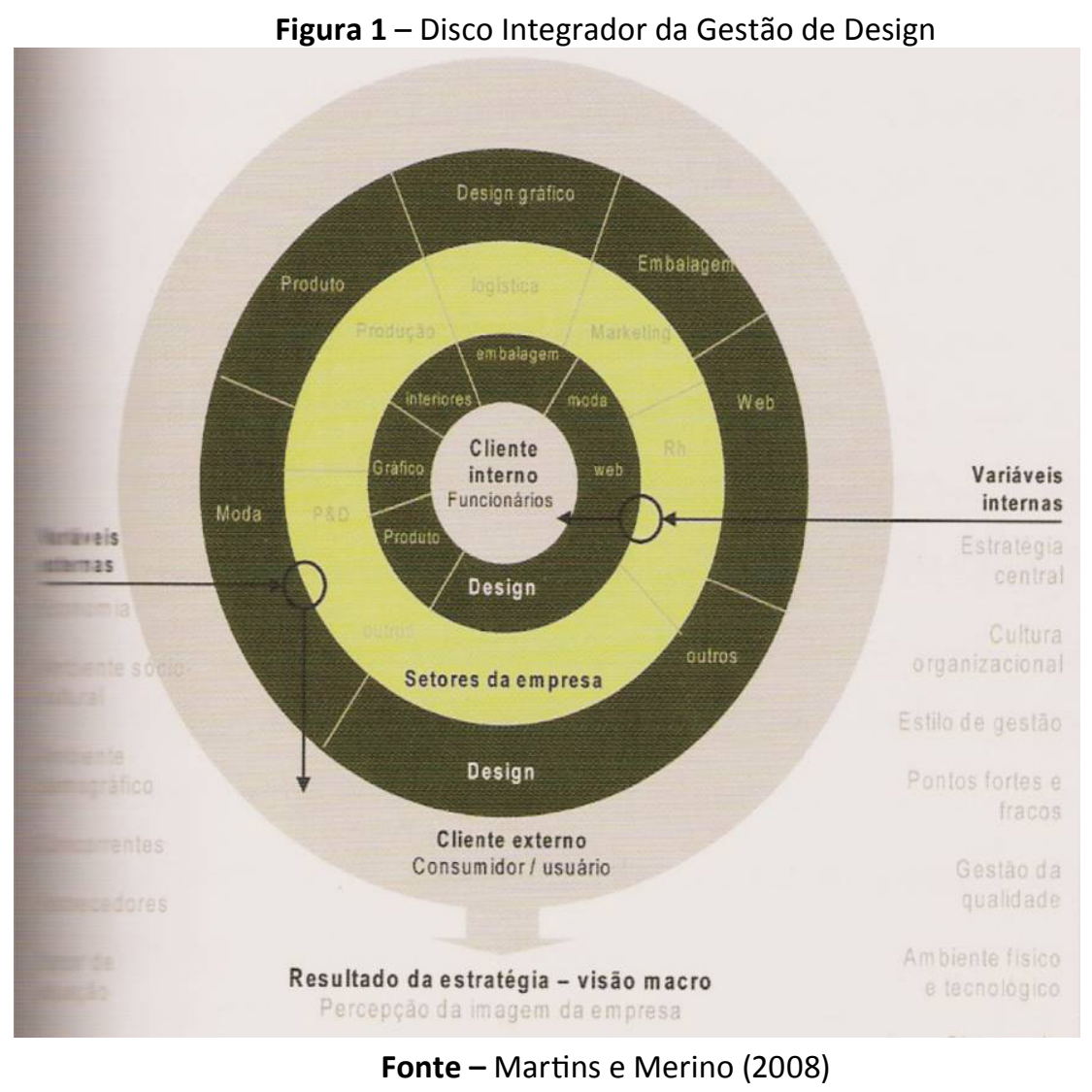

Este modelo pode ser usado como auxílio, ao discriminar as etapas e focos de uma gestão a serem trabalhados, tanto de maneira operacional, quanto estratégica. Além disso, o modelo indica separadamente os setores e suas respectivas áreas, que referem-se tanto ao cliente interno quanto a externo, bem como as tomadas de decisões que envolvem o usuário.

\section{Lançamento de novos produtos}

Em se tratando do lançamento de novos produtos, a prática da gestão do design deve abordar um planejamento estratégico muito bem direcionado, evidenciando os objetivos e metas a serem alcançadas. Além de ser uma atividade importante e que apresenta riscos, envolve áreas de diversas habilidades e interesses que necessitam de atenção, segundo Baxter (1998). São diversos os fatores que determinam a diferença entre o sucesso e fracasso de novos produtos, sendo que Baxter o divide em três grupos principais:

- Orientação para o mercado: O produto deve ter forte diferenciação em relação a seus concorrentes no mercado, e características valorizadas pelos consumidores ou público alvo. No entanto, deve apresentar uma parcela grande de diferenças entre similares, garantindo também um avanço estratégico ao antecipar o produto no mercado.

- Planejamento e especificação: Produtos colocados sob estudos de viabilidade técnica e econômica garantem mais chances de sucesso que aqueles que não recebem a uma análise criteriosa. A viabilidade técnica envolve a disponibilidade de materiais, componentes, processos, produtivos e mão-de-obra qualificada. A viabilidade econômica diz respeito aos investimentos necessários, bem como os custos e o retorno do capital.

Assim, em vista da importância que se faz quanto ao desenvolvimento de um novo projeto, é 
de grande valia a utilização de ferramentas que abordem ao diferencial e á inovação. Delineando-se os aspectos que norteiam o planejamento do produto e sua orientação para o comércio, as provisões a serem tomadas tornam-se menos arriscadas no lançamento de um novo produto.

A estratégia em um planejamento, deve se destinar a novos mercados, e a busca de espaços ainda inexplorados. Conforme Kim (2005) deve-se surpreender em valores e inovação, que segundo ela "é uma nova maneira de raciocinar sobre estratégia, que resulta na criação de um novo espaço de mercado com o rompimento da concorrência".

Kim (2005), em "A Estratégia do Oceano Azul" propõe ferramentas para um planejamento estratégico em que considera a concorrência irrelevante, buscando assim atender demandas e necessidades ainda não exploradas. A inovação de valor é um aspecto chave nessa abordagem, pois busca a diferenciação e a liderança em custos, oferecendo assim também melhores saídas para se resolver os problemas em um empreendimento.

Em um planejamento estratégico é pertinente o uso de ferramentas e tipos de análise para se mensurar os riscos e amenizar as falhas, antes de se dar início ao projeto, pois estas se fazem essencial. Assim, no lançamento de novos produtos pode-se abordar uma série de informações que venham a dar auxílio, tanto durante o desenvolvimento do projeto quanto em uma gestão, tais como:

- Crie um novo espaço inexplorado no mercado, busque o diferencial

- Alie a diferenciação á liderança de custo

- Reduza os custos e aumente o valor percebido para os compradores

- Integre os fatores = utilidade + valor+ custo, equilibrando-os

- Crie ou perceba uma nova demanda a surgir

- Minimize os riscos

- Reoriente seu foco de concorrência de clientes para não-clientes

- Crie facilidades de escolha, surpreenda por meio de um produto inovador

- Preze pelo foco, singularidade e pela mensagem consistente ao mercado destinado

- Faça uma análise dos setores alternativos e sobre os compradores

- Examine os grupos estratégicos em seus respectivos setores

- Examine as ofertas de produtos e serviços complementares

- Analise os apelos funcionais e emocionais dos compradores

- Examine o impacto do negócio em longo prazo

Ao evidenciar a inovação como um processo que deve ser contínuo, a busca pelo diferencial e o modo de solucionar problemas por meio de diferentes abordagens, devem-se consideradas a inspiração, idealização ao pôr em prática, e o desenvolvimento e testes, métodos plausíveis a gerar novas idéias. Neste contexto, o Design Thinking se apresenta como um forte processo, capaz de ampliar os horizontes para novas idéias e meios potenciais para se conduzir o planejamento

São diversas as práticas e abordagens que levam em consideração o Design Thinking como meio de se converter problemas em possibilidades. Muitas delas analisam critérios, ferramentas de criação e até mesmo novos meios de se estar mais em contato com o produto ou serviços oferecidos. Alguns conceitos utilizados são:

- Durante o projeto, pense e repense nos fatores: desejabilidade, viabilidade e praticabilidade - Utilize bons argumentos convincentes para uma boa inovação: inspiração, idealização e implementação.

- Rompa com os paradigmas e facilite a busca por insights

- Tenha uma visão convergente e divergente dos fatos, da análise á síntese e vice-versa

- Desenvolva uma atitude básica de experimentação

\section{Propriedade Intelectual}

A proteção de direitos de propriedade é um apoio legal que confere ao criador de um objeto ou produto, a vantagem e a garantia de que sua invenção permanece protegida sob os aspectos legais. 
A Gestão do Design no gerenciamento do processo de novos produtos: Design Estratégico, ... pedagógico.

O consentimento destes direitos só pode ser autorizado mediante o cumprimento de uma série de recursos que consideram o objeto reinvidicado como autêntico e passível de ser classificado, dentro de padrões técnicos pré-existentes.

No Brasil, o órgão responsável pelo consentimento de concessões de propriedade é o Instituto Nacional de Propriedade Intelectual (INPI), este agente, por meio de dispositivos da Lei Jurídica, submete e encaminha os pedidos de patentes, a exames que apresentam o propósito de considerar sua natureza, conceito, entre outros critérios. O certificado que confere o privilégio de exploração, só pode ser outorgado após uma série de requisitos e discernimentos realizados por esse órgão.

O Livro "Noções gerais sobre Tecnologia e Produtos" (Puhlman, 2004), apresenta as seguintes vantagens e desvantagens com relação ao registro de patentes:

- Vantagens: Garantir uso próprio da invenção sem depender de terceiros; impedir que o concorrente use a invenção; dificultar a "vida" da concorrência divulgando tecnologia, comercializar a invenção gerando retorno em pesquisa; aumento de ativo da empresa; divulgação da empresa e inventores; benefícios fiscais quando houver pagamento de "royalties", assistência técnica, científicos e assemelhados em Institutos de Pesquisa.

- Desvantagens: Divulgação do invento e outras informações sobre a publicação do pedido; Divulgação de Indícios e Planos estratégicos da Empresa; Incerteza na concessão da patente; Custos de manutenção; Prazo de validade determinado.

Também é importante citar o porquê de algumas formas ou aspectos não serem considerados invenções ou modelos de utilidade registráveis. Segundo (Puhlman, 2004) não são passíveis de registros:

- Descobertas, teorias científicas e métodos matemáticos

- Concepções puramente abstratas

- Esquemas, planos, princípios ou métodos, comerciais financeiros, publicitários, educativos (porém, se criados objetos associados, podem ser patenteados)

- Obras literárias, arquitetônicas, artísticas e científicas ou de qualquer criação estética (patenteáveis apenas se tais meios e produtos envolverem em seus efeitos características técnicas)

- Programas de computador (podem receber patentes se possuírem uma seqüência de operações ou diferenciais específicos de componentes)

- Apresentação de informações

- Técnicas e métodos operatórios

- Todo ou parte de seres vivos naturais e materiais biológicos encontrados na natureza, ainda que dela isolados

- O que for contrário á moral e aos bons costumes

- A forma necessária comum ou vulgar do objeto

Antes de se fazer um pedido de registro junto ao INPI, deve ser realizado uma busca antecedente, com o propósito de verificar patentes ou registros já existentes do produto a ser solicitado. Desta forma recomenda-se que essas pesquisas sejam feitas antes e durante o desenvolvimento do projeto, podendo assim aproveitar-se de tecnologias que já se encontram em uso e evitar que esteja sendo realizado um produto já existente. A pesquisa pode ser realizada no junto ao órgão responsável, ou por endereços via internet como no Instituto Nacional de Propriedade Intelectual (INPI), HTTP://www. inpi.gov.br.

Para se tecer um padrão facilitador de registro para um produto, é necessário tomar conhecimento de alguns princípios básicos, na finalidade de promulgar uma ação de registro esclarecedora e eficaz. Conforme Cunha (2000), O pedido de registro é simples, bastando apenas: Preencher o formulário próprio (1.06 - Depósito de Pedido de Registro de Desenho Industrial), este pode ser retirado junto ao órgão ou via internet pelo site, pagar a taxa de depósito, vincular desenhos e fotografias do objeto, sendo estes emitidos em três vias para ser protocolado no INPI. 
Entretanto, os documentos anexados como memorial descritivo, desenhos técnico, relatório, devem seguir rigorosamente especificações e normas, pois ressaltar e evidenciar com objetividade a finalidade do registro de propriedade do produto é um dos aspectos decisivos para que o objeto seja patenteado com sucesso. Dentre as especificações necessárias serão expostas neste artigo, apenas as de maior importância no processo de registro, uma vez que são diversas as particularidades, não sendo possível abordar a todas.

O pedido de registro deve conter informações pertinentes com relação ao produto através de documentos que esclareçam o propósito do produto e elucidem os objetivos e finalidades. $O$ pedido deve conter:

- Requerimento (formulário do INPI)

- Relatório descritivo;

- Reivindicações;

- Desenhos técnicos;

- Resumo;

- Comprovante do pagamento de depósito

O Relatório Descritivo deve conter: descrição objetiva, suficiente e completa, ressaltando os resultados obtidos sobre a natureza do objeto a ser protegido. Ou seja, baseado no relatório é que o exame do objeto será analisado sobre o assunto, para que ocorra a melhor forma de execução do registro. Pulhman (2004) exemplifica em alguns passos como deve ser realizado o relatório:

- Deve ser iniciado pelo título (conciso claro e objetivo)

- Referir-se a uma única invenção, ou a um grupo de invenções de modo a constituir apenas um conceito.

- Referir-se apenas a um modelo principal, podendo conter elementos distintos e adicionais, desde que façam parte do objeto.

- Definir apenas as características ornamentais e variantes da configuração do produto, indicando suas características relevantes.

- Ressaltar a novidade e evidenciar o efeito técnico alcançado

- Relacionar as figuras apresentadas nos desenhos, especificando suas representações.

- O desenho industrial deve ser definido e claro explicitamente quando este não for evidente a partir da descrição da invenção.

Além destes requisitos, também faz parte do pedido, desenhos técnicos que exemplifiquem o produto, sendo necessários os meios de representações de maior adequação, ressaltando os materiais, cortes, vistas, cores e grafismos, se utilizados, com o propósito de facilitar o entendimento do objeto pelo examinador. Todos os documentos exigidos pelo INPI seguem normas técnicas de apresentação e padronizações, o que facilita a disposição das informações, delegando aos documentos maior confiabilidade e dados sucintos.

Conforme Pulhman (2004), após a efetivação do pedido de registro, o pedido fica mantido em sigilo por 18 meses até que a publicação seja emitida na Revista de Propriedade Intelectual (RPI). Após sua publicação, o material se torna acessível ao público. É importante ressaltar que a vigência, após a publicação em RPI, vigora como Registro de Desenho Industrial por 10 anos, a partir da data do depósito, sendo prorrogáveis por três períodos sucessivos a cada 5 anos; a patente de invenção por 20 anos e de 15 para modelo de utilidade.

\section{Sobre a Marcha dos Bichos}

O brinquedo pedagógico, Marcha dos Bichos foi desenvolvido visando à necessidade de se estimular crianças da faixa etária dos sete anos de idade, para que desde cedo fosse trabalhado o sistema motor e cognitivo, auxiliando o desenvolvimento dos movimentos corporais e do raciocínio. 
A Gestão do Design no gerenciamento do processo de novos produtos: Design Estratégico, ... pedagógico.

Seu conceito base, parte do pressuposto que ajudando os infantes a exercitarem suas habilidades em idade escolar, muitas dificuldades de aprendizagem e relacionadas também á motricidade, podem ser resolvidas junto ao seu meio social característico que é a escola.

Todo o brinquedo possui dados e informações coletadas em pesquisas e testes, com a finalidade de satisfazer as percepções e habilidades do público alvo, com foco na ergonomia, e na qualidade dos exercícios propostos, baseados em fundamentações da área pedagógica e pediátrica.

Com base em estudos de metodologia e ferramentas que o Design propicia, o Brinquedo teve como parte de seus objetivos a criação de um produto que fosse acessível por meio de materiais adequados e baratos, de fácil produção por meio de tecnologias acessíveis e acima de tudo, que ofertasse qualidade e segurança ao infante. Outro aspecto de importância que se fez presente no projeto foi o desenvolvimento do projeto sob o delineamento de padrões e normas técnicas, regidos pelo INMETRO (Instituto Nacional de Metrologia, Normalização e Qualidade Industrial).

O brinquedo pedagógico desenvolvido apresenta como diferencial, além das questões visuais que englobam a atividade de Design, a integração entre todos os componentes do jogo, inclusive com relação à embalagem (Bolsa) que apresenta o propósito de facilitar a manutenção e seu transporte pelo infante, assim como o modo facilitado para se guardar os componentes do produto após o uso.

É sabido que os brinquedos destinados às crianças são passíveis de uma série de testes e normas que prezam pela qualidade e segurança dos usuários. Tais preceitos regem objetos produzidos a partir de materiais não tóxicos e que não apresentem perigo ao usuário, sob qualquer circunstância. Deste modo, todos os materiais utilizados no brinquedo proposto são apropriados á prática do divertimento da criança, sem oferecer quaisquer riscos.

Além deste importante fator, a qualidade dos materiais em questão é outro aspecto importante para os pais, visto que o produto deve apresentar durabilidade, sob diversas situações. Por conta desta premissa, e dos processos de fabricação, o custo do produto por unidade pode ser além de vantajoso, uma forma de valorizar ainda mais a invenção, uma vez que os consumidores preferem pagar um pouco mais por produtos de qualidade que apresentam conforto e qualidade para seus filhos.

A falta de materiais de ordem didática e pedagógica nas escolas é outra característica importante a ser ressaltada sobre o brinquedo proposto. Em meio a pesquisas executadas durante o projeto, educadores e professores entrevistados destacaram a falta de instrumentos e ferramentas de auxílio em meio escolar, que suprissem uma atividade mais prazerosa aos alunos.

Esse fato é visível em instituições públicas, que carecem de práticas e recreações que tenham como finalidade o aprendizado por meio de jogos ou brinquedos específicos. Muitas vezes essas atividades são geridas e propostas pelos educadores, a partir de indicações de livros, mas muitas vezes "inventadas" por eles, no propósito de tornar o ensino menos tedioso e cansativo ás crianças.

Assim, o propósito do brinquedo em questão é dar apoio e auxilio no desenvolvimento do público alvo, por meio de atividades facilmente realizadas por eles, buscando melhorar e aumentar suas capacidades motoras e cognitivas. Além disso, incorpora diversos valores de qualidade, durabilidade e segurança que se fazem importantes tanto à criança, quanto aos pais, objetivando também suprir uma necessidade de materiais específicos á prática do ensino.

\section{Metodologia}

A metodologia em presente artigo foi de natureza exploratória, realizadas junto a órgãos responsáveis, no intuito de se alcançar um levantamento de informações que acercam os aspectos importantes quanto ao requerimento de testes, avaliações e procedimentos para se implantar normas, padrões de fabricação e processos da legalidade intelectual para registro de um produto.

Por meio do Instituto de Pesos e Medidas (IPEM) e Agência de Inovação Tecnológica da UEL (AINTEC), ambos situados na cidade de Londrina-PR, foram realizados entrevistas, com base em um roteiro composto por questões e perguntas abertas, com o propósito de deixar a pessoa entrevistada mais à vontade, e proporcionar maior aproveitamento ao valor das informações coletadas.

A entrevista foi realizada seguindo técnicas específicas conforme lida (2005), em obter as informações desejadas, redirecionando a conversa aos aspectos importantes. Através de um roteiro 
VIEIRA, Alexandre Jr. Franco

pré-estabelecido, como roteiro de perguntas e dados a serem obtidos, fez-se uma das técnicas utilizada para flexibilizar o tempo disponibilizado pelos responsáveis, sendo necessário, portanto direcionar as questões de relevância.

No IPEM, O entrevistado foi o Gerente Geral, Sr. Jair Ciquino, responsável pela administração da unidade do Instituto Nacional de Metrologia, Normalização e Qualidade Industrial (INMETRO) unidade de Londrina, no dia 12/05/2011. Segundo ele, o INMETRO tem por função apenas certificar e validar o produto, cedendo os selos e documentações necessárias, que asseguram a qualidade do produto e o aprovam para a legalidade e comércio.

Para se certificar um Produto, no caso em questão um brinquedo, primeiramente deve ser realizada uma análise do produto em um Organismo de Certificação de Produtos (OCP) indicado pelo INMETRO, onde devem ser desempenhados os devidos testes e ensaios, que seguem normas padronizadas como a NM 300-1; NM 300-2 e 300-3, referentes á segurança e qualidade dos brinquedos. Esses ensaios padrões, conforme entrevistado, visam preservar a saúde e a segurança da criança, em testes que levam em consideração o material, tinta, embalagem, componentes, formas e qualquer aspecto do produto que ofereça risco ao infante.

Após os devidos procedimentos o OCP deve então emitir um Certificado e Autorização do Selo de Identificação da Conformidade, conforme a Portaria no 321, Art 9o do Ministério do Desenvolvimento, Indústria e Comércio Exterior, que atesta o processo de testes e ensaios para a certificação e comércio. Somente após a certificação pelo órgão indicado é que pode ser dada a entrada de Certificação do produto pelo INMETRO, garantindo assim que o brinquedo é livre de riscos á criança, e, portanto aprovado para o comércio.

O INMETRO, depois de emitido a certificação pelo órgão responsável, realiza a autenticação do produto, podendo realizar uma fiscalização sobre a produção, através de coleta de amostras no mercado. Quaisquer mudanças de materiais utilizados ou componentes modificados devem ser informadas imediatamente ao OCP ou INMETRO, pois o brinquedo pode ser retirado de sua comercialização e ser passível de penalidade conforme a Lei 9933/1999.

Em entrevista realizada no dia 26/05/2011, com Sr. Ciro Osawa, especialista e Diretor do Escritório de Propriedade Intelectual da AINTEC, para que o Registro da Propriedade Intelectual seja efetivado de maneira dinâmica, uma série de aspectos com relação ao produto, deve ser abordado primeiramente a natureza do item a ser registrado.

Devem ser analisados apenas o desenho de formas, seu conjunto e ornamentos, não sendo relevante a funcionalidade. Entretanto, combinações originais e características próprias dos objetos, devem prezar pela novidade além de serem passíveis e aplicáveis em processos Industriais conhecidos.

Primeiramente, deve-se realizar um pedido de registro da forma, por meio de imagens, desenho técnico e memorial descritivo (este que deve se restringir ás características peculiares sobre a forma ornamental), ou seja, aspectos que evidenciam a representação do produto a ser registrado. 0 pedido de registro acompanha o valor de $\mathrm{R} \$ 80,00$ (Oitenta Reais) sendo segura sua propriedade por dez anos, a partir da data do depósito, e passível de prorrogação por mais três qüinqüênios.

Entretanto, a concessão da propriedade só é válida a partir da emissão do Certificado de Registro, processo que leva três anos para ser realizado, visto que o órgão responsável realiza neste período a avaliação e tramitação necessária, inclusive nulidade de pedido se este for indeferido. Caso já exista, uma proteção a um determinado produto, e este tenha sido passível de uso, com ganhos e lucros obtidos, o proprietário do Registro deve receber todo dinheiro recebido acerca de sua propriedade até o momento.

Desse modo, faz-se necessário lembrar que antes de se efetuar um pedido de depósito é conveniente realizar uma busca junto ao INPI, a fim de verificar a existência de registros anteriores. Por meio da Revista da Propriedade Intelectual (RPI), que concede publicações e informações simplificadas sobre registros de desenhos, pode ser feita uma busca a fim de aferir também o andamento do pedido.

$O$ registro é concedido por meio de avaliação de natureza diferenciada, bem como valores de depósito e procedimentos. Para se realizar o registro de marca, dá-se primeiramente entrada no "depósito de patente", que segundo Lima (2007), tende a ficar sob sigilo por dezoito meses, para posteriormente ser publicado na RPI, mas pode ser antecipada sob requerimento após seis meses da 
A Gestão do Design no gerenciamento do processo de novos produtos: Design Estratégico, ... pedagógico.

data de depósito.

Para registro de Carta Patente são necessários: Requerimento, relatório (quando necessário), reinvidicações quando necessário, campo de atuação, desenhos e/ ou fotografias. O requerimento deve seguir o formulário emitido pelo INPI, seguido de relatório com as especificações acerca do produto, em forma de memorial descritivo com informações necessárias ao encaminhamento do processo.

As reinvidicações não são obrigatórias, entretanto o campo de atuação necessita da descrição das áreas e finalidades á qual a marca irá atuar no mercado, produtos ou formas plásticas em questão. É fundamental que desenhos, fotografias importantes para o registro da marca e seu uso seja anexo como parte das informações reinvidicadas.

Em caso de registro de Marca, um requisito básico é ser novidade, mas com originalidade, sem remeter a marcas anteriores. São classificadas pela sua natureza (Marca de Produto, Certificação e Coletiva) e pelo seu tipo de apresentação (Nominativa, formada por palavras; Figurativa, que constitui símbolo ou sinal gráfico; Mista, composta tanto por letras e quanto figuras; Tridimensional, formada por uma configuração volumétrica do produto), conforme Silveira (2011).

O primeiro passo ao se realizar um registro de marca é o preenchimento do requerimento, onde devem constar as informações necessárias para que o processo possa ser encaminhado. Também deve apresentar quinze etiquetas (de tamanho $6 \times 6 \mathrm{~cm}$, com marca no tamanho não maior que $5 \mathrm{~cm}$ ) em fundo branco e com preenchimento em preto, que se necessário a presença de cores, essas devem ser indicadas com um traço fino e nomeado o nome da cor.

Segundo Silveira (2011), uma série de comprovantes deve acompanhar o registro da marca como cópia do contrato social da empresa e Contrato Nacional de Pessoa Jurídica (CNPJ), Regulamento de Utilização para marca de produto, Descrição de características fundamentais no caso de marca coletiva ou tridimensional. É conveniente mencionar que o registro da marca só pode ser efetivado, desde que tenha comprovação de atividade exercida pela empresa, o que explana as exigências de documentações.

Uma vez realizado o depósito do pedido, este já pode ser publicado na RPI, e não existindo contestação no prazo de sessenta dias o Certificado de Registro já pode ser emitido. O valor de depósito para Registro de marca é de $\mathrm{R} \$ 120,00$ (Cento e vinte reais), entretanto sua duração é de período indeterminado tendo duração mínima de dez anos, mas podendo ser prorrogada sucessivamente em períodos iguais.

\section{Análise}

Diante das informações expostas acerca do planejamento, registro de propriedade intelectual e certificação de produtos, é necessário um exame desses aspectos, a fim de selecionar os pontos básicos e mais específicos do processo. Deste modo, limitando assim características de maior amplitude e que requerem um estudo mais moroso, por requerer atenção a diversos artigos da lei, procedimentos para a certificação e um programa peculiar para a Gestão de Design.

Faz se importante ainda com relação ao planejamento do projeto e durante, buscar forte embasamento para uma boa inovação, inspiração e idealização, mas sempre em contraste com fatores como o desejo, viabilidade e praticabilidade. Ao visar esses elementos deve-se sempre manter uma posição de crítica que converge e diverge diante dos fatos e da realidade do projeto.

A respeito do direito de Propriedade Intelectual e de suas respectivas viabilidades e Registros, deve ser de atento do requerente ou do procurador, a classificação á qual o produto ou imagem se enquadra perante os aspectos legais, e suas devidas definições, tanto para desenho industrial quanto para o registro de marca.

Os pontos evidentes para se realizar um registro de propriedade, concernem a documentações próprias para cada natureza do objeto a ser requerido, bem como suas particularidades, descrições e requisitos básicos para devida avaliação pelo órgão responsável. A busca por registros anteriores se faz fundamental, visando eliminar riscos ao se requerer um pedido de registro de um objeto ou imagem já existente, evitando assim uma nulidade do processo.

Outro fator de grande importância se dá com relação aos posteriores usos após a certificação 
de propriedade do requerente, pois se deve atentar aos prazos de validade do registro. Estes podem ser prorrogados ou ainda passivos de nulidade, vindo a cair em conhecimento público, conforme aspectos específicos na lei do código de propriedade intelectual.

Quanto aos testes para certificação e comércio do produto, estes devem ser devidamente requeridos em órgãos credibilizados pelo Inmetro, no intuito de serem realizadas as avaliações e medições necessárias. Somente após a certificação pelos órgãos responsáveis pelos testes, é que o Inmetro poderá estabelecer uma análise quanto á classificação do produto e sua liberação a ser comercializado.

Vale lembrar que é imprescindível ao requerer a certificação por estes órgãos, as documentações necessárias e os devidos certificados e selos emitidos pelo mesmo, pois o produto é passível de quaisquer testes de qualidade mesmo estando em comercialização, com a finalidade de se buscar quaisquer mudanças do produto que prejudiquem aspectos morais, éticos, bem como a segurança do consumidor e do público alvo.

\section{Proposta de Modelo “DPC"}

Visando atender as etapas e propostas de planejamento para o lançamento de um produto inovador, foi elaborado o "Dispositivo de Planejamento e Certificação" (DPC) em esquema gráfico (Figura 02) que auxilia a o planejamento no lançamento de um novo produto e indica as fases pertinentes do processo de registro intelectual, para que o produto possa ser protegido e comercializado sob o amparo da legislação.

Com a finalidade de se facilitar a leitura do diagrama e das fases que envolvem cada objetivo do planejamento e registro foi criado quatro campos, em que cada cor evidencia a uma fase da gestão do processo de lançamento de um novo produto. As áreas distintas que se fazem presentes podem ser seguidas de modo aleatório, pois cada uma independe da outra em suas ações específicas. No entanto é conexo afirmar que em uma gestão, o início se dá pelo campo do planejamento, sendo o registro de marca o último a ser explorado.

Figura 02 - Dispositivo de Planejamento e Certificação de Produtos

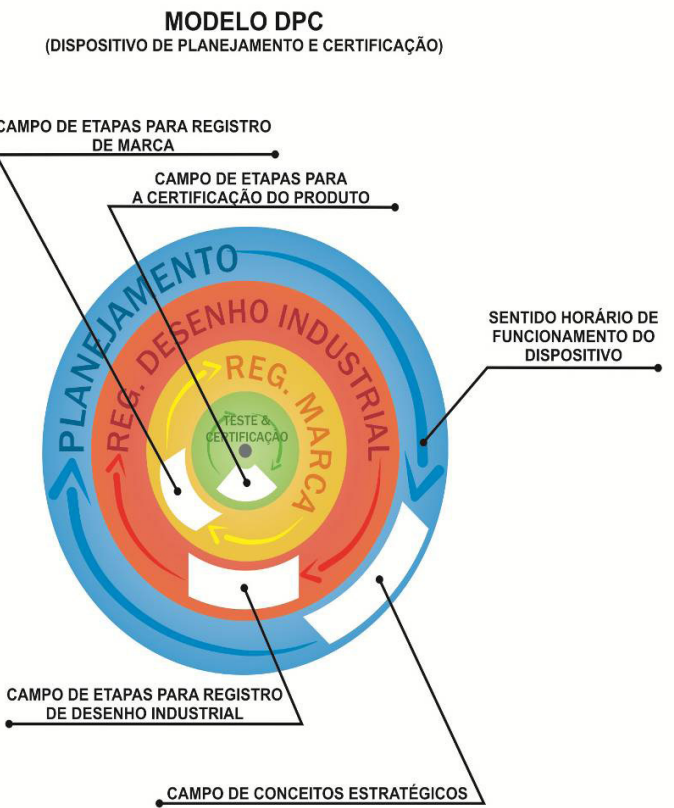

Fonte: Própria

O modelo "DPC" foi elaborado de modo a facilitar tantos as estratégias de lançamento de 
A Gestão do Design no gerenciamento do processo de novos produtos: Design Estratégico, ... pedagógico.

um novo produto, quanto o entendimento das etapas que se fazem necessárias para o registro de propriedade intelectual e certificação de um produto. É um dispositivo direcionado a auxiliar a Gestão de Design de um produto, baseado em dicas e sugestões estratégicas para o planejamento, e a esclarecer as etapas e fases pertinentes para o comércio.

O dispositivo funciona ao ser girado em sentido horário, apresentando em cada campo específico as dicas e sugestões para o planejamento, ou mostrando ordenadamente as etapas para registro ou certificação de um produto ou marca, para cada área em específico. Apenas a área delimitada para o planejamento contém informações que independem do sentido indicado a ser utilizado, sendo que os demais campos (Registro de Desenho Industrial e Marca e Certificação) devem-se respeitar o sentido proposto, a fim de direcionar etapas do processo.

A Área de cor azul refere-se ao campo do planejamento. Neste espaço estão contidas as informações que podem vir a ser muito proveitosas na elaboração de um programa que visa o lançamento de um produto com diferencial e inovação. Vale lembrar que a manobra a ser traçada e suas respectivas ações, devem sempre seguir ferramentas mais completas acerca da gestão de um novo produto.

O espaço vermelho é destinado ao Registro de Desenho Industrial, e nele se confere as etapas as quais o registro segue até a emissão do certificado de propriedade. $O$ espaço amarelo confere as etapas do registro de marcas bem como as documentações necessárias, presentes em todas as áreas para registro e testes do produto. O espaço verde diz respeito ao das fases para se legitimar o produto com aprovação notória para ser comercializado.

\section{Conclusão}

O presente estudo apresentou a importância de um planejamento baseado na Gestão do Design, envolvendo diversos aspectos relacionados ao produto, tanto para o desenvolvimento do projeto, quanto durante e após sua execução. Ao propor padrões de planejamento que permitam diversos conceitos a serem implantados em um programa de gestão, fez-se notório que fossem apresentados os meios pelos quais o produto pode ser registrado como fruto de propriedade intelectual, bem como as etapas para que seja certificado e próprio a ser comercializado.

As informações acerca da Gestão do Design e de lançamento de novos produtos foram complementares como embase para propor e direcionar o planejamento estratégico, por meio de métodos e conceitos no propósito de promover a inovação e o diferencial, ao lidar com projeto de novos produtos. Fica evidente frente ao exposto, a necessidade que se faz de um programa de gestão que seja bem elaborado, com o intuito de se alcançar os objetivos e metas traçados no plano.

Sobre o registro de Propriedade intelectual, verificou-se que é fator imprescindível para garantir a proteção da obra, sejam eles o Desenho Industrial ou a Marca propriamente dita. As leis sobre o Direito da Propriedade Intelectual corroboram o autor da obra em diversos aspectos, entretanto deve ser de conhecimento da pessoa física ou jurídica, sobre quais termos legais o registro pode estar amparado. A descrição e os requisitos necessários devem ser elaborados de modo a facilitar o entendimento do avaliador pelo objeto requerido.

Foi constatado que o consentimento da certificação de Propriedade Intelectual é um processo demorado e custoso, no caso de Desenho Industrial, e por isso deve-se estar sempre atento ás publicações. A nulidade do processo pode ser requerida ou aplicada, se houver qualquer incidente prescrito em lei á que conceda esta ação, logo, toda documentação e acompanhamento devem ser realizados com freqüência, junto ao órgão responsável.

Averiguou-se uma série de etapas que prezam pela qualidade do produto e a segurança do público alvo, bem como a emissão de selos e certificação pelo INMETRO. Dentre elas, além de testes de material e documentação, se faz necessária a classificação adequada á categoria do brinquedo proposto. O comércio do produto, portanto só é regularizado com as devidas providências frente aos testes, certificação e selagem do produto.

Outro fator de grande importância dá-se quanto à utilização do Direito de Propriedade como parte do Planejamento estratégico, bem como a certificação, a fim de garantir os respaldos do produto 
VIEIRA, Alexandre Jr. Franco

perante a Lei. Deste modo, esses aspectos legitimam e conferem sustentação adequada para a devida divulgação e comércio, protegendo o direito tanto do consumidor e público alvo, quanto do criador do produto.

O Dispositivo criado proporcionou de modo facilitador o entendimento das etapas pertinentes ao registro de Propriedade Intelectual e Certificação para comércio do produto, exemplificando os requisitos e as fases de cada processo. O planejamento é abordado no diagrama de modo a oferecer diversos conceitos-chaves ao se elaborar um plano de gestão que vise o lançamento de produtos inovadores e com diferencial.

A participação dos entrevistados da área de Propriedade Intelectual e de Medição e Qualidade foi fator de grande auxílio para definir os aspectos mais importantes e seus procedimentos, logo, o dispositivo criado oferece apenas uma brevidade acerca das etapas dos processos. Quaisquer informações específicas ou detalhes sobre as áreas dispostas devem ser encaminhadas pelos artigos e incisos da lei, também encontrados nos respectivos órgãos responsáveis.

O projeto do brinquedo didático/pedagógico exposto como conjectura de uma Gestão de Design, apresenta importância pertinente a ser considerada como modelo de aplicação em escolas e sistemas de ensino, dado que o desenvolvimento do produto ocorreu junto ao meio educacional, portanto desenvolvido e testado com o público alvo em escolas.

\section{Referências}

BAXTER, Mike. Projeto de Produto, Guia prático para o desenvolvimento de novos produtos. 2ªed., São Paulo. Edgar Blücher Ltda, 2000. 260p.

BROWN, Tim. Design Thinking: uma metodologia poderosa para decretar o fim das velhas idéias. Tradução Cristina Yamagami. - Rio de Janeiro: Elsevier, 2010.

CUNHA, Frederico Carlos da. A Proteção Legal do Design: propriedade industrial. Rio de Janeiro: Lucerna, 2000

HARRISON, Tony. Manual do Gestor de Produto. Presença, 1aed. 1990.

IIDA, Itiro. Ergonomia: Projeto e Produção. 2ed. São Paulo: Edgar Blücher, 2005.

LIMA, João Ademar de Andrade. Curso de propriedade intelectual para designers. João Pessoa: Idéia, 2001.

KIM,W.Chan. A estratégia do Oceano azul: como criar novos mercados e tornar a concorrência irrelevante. ; tradução de Afonso Celso da Cunha Serra. Rio de Janeiro: Elsevier, 2005 - 23a impressão.

MAGALHÃES, C. Design estratégico: integração e ação do Design Industrial. Estudos em Design. Vol. III, n. 1, Julho de 1997. P. $15-27$.

MARTINS, R. F. F.; MERINO, Eugenio Andrés Dias. A gestão de design como estratégia organizacional. Londrina: EDUEL, 2008.

NEWTON, Richard. O gestor de projetos; tradução: Daniel Vieira, São Paulo: Pearsons Prentice Hall, 2011.

PHILLIPS, Peter L. Briefing: a gestão do projeto de design; tradução Itiro lida; São Paulo: Edi- 
tora Blucher, 2007.

PULHMAN, Angela Cristina Azanha. Noções gerais sobre proteção de tecnologia e produtos: versão inventor; textos Cladio Fuentes Moreira. São Paulo: Instituto de pesquisas Tecnológicas, 2004.

SILVEIRA, Newton. Propriedade industrial, direito do autor, software, cultivares, nome empresarial. 4. ed.rev. ampl, Barueri, SP: Manole, 2011.

VIEIRA. Alexandre Júnior Franco. Brinquedo para auxiliar o desenvolvimento psicomotor infantil. Trabalho de conclusão de curso apresentado ao departamento de Design e Moda, Centro de Tecnologia da Universidade Estadual de Maringá, 2009. 